\title{
Effect of a Caregiver's Education Program on Stroke Rehabilitation
}

\author{
Sang-Eun Hong, MD, Chang-Hwan Kim, MD, Ee-jin Kim, MD, Kyung-Lim Joa, MD, Tae-Hyun Kim, OTR, \\ Sang-Keun Kim, RPT, Hee-Jun Han, MD, Eui-Chang Lee, MD, Han-Young Jung, MD
}

Department of Physical and Rehabilitation Medicine, Inha University School of Medicine, Incheon, Korea

\begin{abstract}
Objective To evaluate effects of caregiver's education program on their satisfaction, as well as patient functional recovery, performed in addition to daily conventional rehabilitation treatment.

Methods Three hundred eleven subjects diagnosed with first-onset stroke and transferred to the Department of Physical Medicine and Rehabilitation of Inha University Hospital were surveyed. In 2015, caregivers attended an education program for acute and subacute stroke patients. Patients who received an additional rehabilitation therapy were assigned to the experimental group $(n=81)$, whereas the control group $(n=100)$ consisted of transfer cases in 2014 with only conventional treatment. The experimental group was classified by severity using the Korean version of the National Institutes of Health Stroke Scale (K-NIHSS), which was administered to all 181 subjects, in addition to, the Korean version of the Mini Mental Status Examination (K-MMSE), a Modified Barthel Index (K-MBI), and the Berg Balance Scale (K-BBS). Caregiver satisfaction and burden before and after education programs were assessed using the Canadian Occupational Performance Measure (COPM), as well as family burden and caregiver burnout scales.

Results No significant intergroup difference was observed between initial K-NIHSS, K-MMSE, K-BBS, K-MBI scores, and times from admission to transfer. Those with moderate or severe strokes under the experimental condition showed a more significant improvement than the control group as determined by the K-NIHSS and K-BBS, as well as tendential K-MMSE and K-MBI score increases. Satisfaction was significantly greater for family members and formal caregivers of patients with strokes of moderate severity in the experimental group.

Conclusion The caregiver's education program for stroke subjects had a positive outcome on patients' functional improvement and caregiver satisfaction. The authors believe that the additional rehabilitation therapy with the education program aids patients to achieve functional improvements for an optimal return to social life.
\end{abstract}

Keywords Stroke, Rehabilitation, Caregiver, Rehabilitation outcome

Received May 27, 2016; Accepted July 5, 2016

Corresponding author: Han-Young Jung

Department of Physical and Rehabilitation Medicine, Inha University School of Medicine, 27 Inhang-ro, Jung-gu, Incheon 22332, Korea. Tel: +82-32890-2486, Fax: +82-32-890-2486, E-mail: rmjung@inha.ac.kr

ORCID: Sang-Eun Hong (http://orcid.org/0000-0002-9433-6642); Chang-Hwan Kim (http://orcid.org/0000-0003-2557-6025); Ee-jin Kim (http://orcid. org/0000-0001-6604-6907); Kyung-Lim Joa (http://orcid.org/0000-0002-3747-9831); Tae-Hyun Kim (http://orcid.org/0000-0002-1738-7729); SangKeun Kim (http://orcid.org/0000-0002-1383-9943); Hee-Jun Han (http://orcid.org/0000-0003-4326-1617); Eui-Chang Lee (http://orcid.org/0000-00027383-0713); Han-Young Jung (http://orcid.org/0000-0003-1428-9821).

(a) This is an open-access article distributed under the terms of the Creative Commons Attribution Non-Commercial License (http://creativecommons.org/ licenses/by-nc/4.0) which permits unrestricted noncommercial use, distribution, and reproduction in any medium, provided the original work is properly cited. Copyright $\odot 2017$ by Korean Academy of Rehabilitation Medicine 


\section{INTRODUCTION}

Stroke is prevalent among the elderly and a main cause of severe chronic disabilities. The Korea National Health Insurance Service reported that cerebrovascular disease is the third most common disease following cancer and cardiac disease (48.2 persons per 100,000 of the population) in 2014 , but mortality rates due to cerebrovascular disease were lower than in 2004. Regarding the latter, acute management including medical treatment (e.g., recombinant tissue plasminogen) and organized interdisciplinary care has improved, and mortality rates decreased accordingly [1]. However, despite such relatively successful acute medical management, the majority of stroke patients suffer life-long disability [2]. In a previous long-term study, it was reported that $25 \%-74 \%$ of stroke survivors required assistance to perform activities of daily living (ADL) including feeding, self-care, and mobility [3].

Considering the prevalence of cerebrovascular disease and residual disability, in stroke, interdisciplinary comprehensive rehabilitation intervention is considered a major management modality for poststroke care, so this type of intervention has increasingly been asked for [4]. The effect of interdisciplinary comprehensive rehabilitation is strengthened by reiteration and intenseness (highintensive practice and repetitive task oriented training) $[4,5]$. However, in Korea, a 5-day work week system has been adopted and most hospitals cannot perform rehabilitation therapy at weekends.

Previous reviews have reported that additional exercise programs by therapists at weekends could improve functional recoveries after stroke $[6,7]$. Thus, it stood to reason that additional rehabilitation therapy based on a caregiver's education program could improve functional recovery after stroke. Accordingly, the purpose of this study was to evaluate the effects of rehabilitation therapy on patients' functional recovery by caregivers and the latter group's satisfaction, in addition to daily conventional rehabilitation treatment.

\section{MATERIALS AND METHODS}

\section{Enrolment of subjects}

Three hundred eleven subjects with acute and subacute stroke diagnosed at first-onset at Inha University Hospital between 2014 and 2015 were and treated in a Department of Physical and Rehabilitation Medicine and recruited for the present study. Subjects hospitalized within 72 hours from disease onset which was considered the time of admission were included. The 181 patients remaining after exclusions constituted the study group and were assigned to an experimental $(n=81)$ or control group $(n=100)$. In 2015, rehabilitation therapy based on a caregiver education program for acute and subacute stroke in addition to conventional rehabilitation therapy was performed and these patients comprised the experimental group, while subjects transferred in 2014 who had only undergone conventional rehabilitation therapy were assigned to the control group.

\section{Subgroups of the subjects}

Eighty-one patients in the experimental group were divided according to disease severity as determined by KNIHSS scores, that is: a mild subgroup ( $\mathrm{n}=22$; scores $1-4$ ), a moderate one $(n=44$; scores $5-15)$, as well as a severe category $(n=15$; scores $\geq 16)[8]$.

\section{Interventions}

All patients in the control and the experimental groups received two sessions of daily conventional rehabilitation therapy ( 5 days/week for 4 weeks). One session consisted of both physical and occupational therapies, as well as occasionally speech therapy for a half hour, all in all one and a half hours. Patients in the experimental group received additional rehabilitation therapy based on the education programs, which included family member(s) or a formal caregiver, organized by physiatrists and performed by physiotherapists as well as occupational therapists when the transfer to the Department of Physical and Rehabilitation Medicine took place. The education programs were organized according to stroke severity as detailed in Table 1.

The additional rehabilitation therapies provided by caregivers were performed for 10-20 minutes after dinner on weekdays and after breakfast and as well as supper on weekends, and were conducted for 4 weeks after completing the education program.

\section{Measurements}

Initial and discharge Korean version of the National Institutes of Health Stroke Scale (K-NIHSS), the Mini- 
Table 1. The education program of caregivers for physical and occupational activities

\begin{tabular}{|c|c|c|}
\hline \multirow{2}{*}{$\begin{array}{l}\text { Stroke severity } \\
\text { (K-NIHSS) }\end{array}$} & \multicolumn{2}{|c|}{ Educational contents } \\
\hline & Physical activities & Occupational activities \\
\hline Severe $(\geq 16)$ & $\begin{array}{l}\text { Passive ROM exercise } \\
\text { Assistant rolling and sitting } \\
\text { Assistant axial strengthening exercise } \\
\text { in supine position }\end{array}$ & $\begin{array}{l}\text { Improvement of awakeness through sensory } \\
\text { stimulation } \\
\text { Upper extremities ROM exercise, truncal } \\
\text { balance training } \\
\text { ADL training is not included }\end{array}$ \\
\hline Moderate (5-15) & $\begin{array}{l}\text { Active ROM exercise in supine position } \\
\text { Exercise in lateral lying position } \\
\text { Active axial strengthening exercise } \\
\text { in supine position }\end{array}$ & $\begin{array}{l}\text { Cognition: memory, orientation, concentration } \\
\text { improvement } \\
\text { Upper extremities: functional improvement, } \\
\text { truncal balance, endurance training } \\
\text { ADL training: mainly simple activity }\end{array}$ \\
\hline Mild (1-4) & $\begin{array}{l}\text { Active axial strengthening exercise } \\
\text { in supine position } \\
\text { Active exercise in sitting and standing position }\end{array}$ & $\begin{array}{l}\text { Executive function, higher level cognition } \\
\text { domain } \\
\text { Fine motor training, endurance, standing } \\
\text { balance, gait training } \\
\text { ADL training: mainly using tool, return to society } \\
\text { and the workplace }\end{array}$ \\
\hline
\end{tabular}

K-NIHSS, Korean version of the National Institutes of Health Stroke Scale; ROM, range of motion; ADL, activities of daily living.

Mental Status Examination (K-MMSE), a Modified Barthel Index (K-MBI), and the Berg Balance Scale (K-BBS) scores were obtained for all 181 study subjects. We also documented times from admission to transfer.

First evaluations were conducted within 3 days of transfer to the Department of Physical and Rehabilitation Medicine, and discharge assessments were performed within 3 days at or following discharge. In addition to control and experimental group comparisons, caregiver satisfaction was measured using the Canadian Occupational Performance Measure (COPM) [9], caregiver burden employing the family burden scale (5-point scale) [10], and the caregiver burnout scale (5-point scale) [11] before and after education.

\section{Statistics}

Statistical analyses were performed using SPSS ver. 18 for Windows (SPSS Inc., Chicago, IL, USA) and statistical significance was determined for $p$-values $<0.05$. The Mann-Whitney test was used to compare the K-NIHSS, $\mathrm{K}$-MMSE, K-BBS groups, as well as K-MBI scores and the patients' age at transfer. The Student t-test was used to compare hospital stay durations and pre- to post-intervention differences for K-NIHSS, K-MMSE, K-BBS, and KMBI scores between the control and experimental groups according to stroke severity. The paired t-test compared caregiver satisfactions and burdens before and after intervention in the experimental group.

\section{RESULTS}

\section{Participants}

At the beginning of the study, 178 and 133 stroke patients were enrolled in the control and experimental groups, respectively. However, 52 patients initially assigned to the experimental group were excluded for the following reasons: early discharge $(<1$ month) for 44 , refusal to participate for 7 , as well as one foreigner. Consequently, 81 patients were recruited for the experimental group: 55 had ischemic stroke (23 male, 32 female) and 26 hemorrhagic stroke (13 male, 13 female). The experimental subgroups were determined as follows: $22 \mathrm{had}$ suffered a mild stroke, 44 with a moderate, and 15 with a severe one. With regard to the 81 caregivers, 21 were family member(s) and 60 formal caregivers (Table 2).

In the control group, 78 patients were excluded because of early discharge; thus, 100 patients were included. No significant differences was observed between the experimental and control groups with respect to the beginning and the discharge K-NIHSS, K-MMSE, K-BBS, and K-MBI scores, as well as with regard to the time from admission to transfer (Table 3). 
Table 2. Characteristics of subjects and caregivers according to severity

\begin{tabular}{|c|c|c|c|c|c|c|c|}
\hline \multirow{2}{*}{$\begin{array}{l}\text { Stroke severity } \\
\text { (K-NIHSS) }\end{array}$} & \multirow{2}{*}{$\begin{array}{c}\text { No. of } \\
\text { subjects }\end{array}$} & \multicolumn{2}{|c|}{ Cerebral infarction } & \multicolumn{2}{|c|}{ Cerebral hemorrhage } & \multicolumn{2}{|c|}{ Caregivers } \\
\hline & & Male & Female & Male & Female & Family & Formal \\
\hline Mild (0-4) & 22 & 5 & 12 & 3 & 2 & 6 & 16 \\
\hline Moderate (5-15) & 44 & 13 & 17 & 7 & 7 & 10 & 34 \\
\hline Severe $(\geq 16)$ & 15 & 5 & 3 & 3 & 4 & 5 & 10 \\
\hline Total & 81 & 23 & 32 & 13 & 13 & 21 & 60 \\
\hline
\end{tabular}

K-NIHSS, Korean version of the National Institutes of Health Stroke Scale.

Table 3. Comparisons of age, K-NIHSS, K-MMSE, K-BBS, K-MBI in two groups at transfer to and discharge from the Department of Physical Medicine and Rehabilitation

\begin{tabular}{|c|c|c|c|c|c|c|}
\hline & \multicolumn{3}{|c|}{ Transfer } & \multicolumn{3}{|c|}{ Discharge } \\
\hline & $\begin{array}{l}\text { Control } \\
(n=100)\end{array}$ & $\begin{array}{c}\text { Experimental } \\
(n=81)\end{array}$ & p-value ${ }^{a}$ & $\begin{array}{l}\text { Control } \\
(n=100)\end{array}$ & $\begin{array}{c}\text { Experimental } \\
(n=81)\end{array}$ & p-value ${ }^{a}$ \\
\hline Age (yr) & $62.83 \pm 13.84$ & $64.52 \pm 14.69$ & 0.82 & - & - & - \\
\hline Days to transfer & $31.13 \pm 20.29$ & $32.02 \pm 12.12$ & 0.78 & - & - & - \\
\hline Transfer to discharge (day) & - & - & - & $31.3 \pm 18.8$ & $30.0 \pm 21.3$ & 0.80 \\
\hline K-NIHSS & $8.76 \pm 4.94$ & $9.04 \pm 5.57$ & 0.32 & $5.7 \pm 5.0$ & $4.3 \pm 4.6$ & 0.20 \\
\hline K-MMSE & $14.44 \pm 10.33$ & $13.58 \pm 10.55$ & 0.42 & $19.2 \pm 9.4$ & $18.1 \pm 10.6$ & 0.46 \\
\hline K-BBS & $9.72 \pm 13.10$ & $8.78 \pm 12.87$ & 0.72 & $29.6 \pm 18.3$ & $25.7 \pm 19.6$ & 0.29 \\
\hline K-MBI & $17.24 \pm 18.60$ & $13.87 \pm 17.85$ & 0.58 & $39.4 \pm 27.7$ & $36.5 \pm 26.6$ & 0.48 \\
\hline
\end{tabular}

Values are presented as mean \pm standard deviation.

K-NIHSS, Korean version of the National Institutes of Health Stroke Scale; K-MMSE, Korean version of Mini-Mental Status Examination; K-BBS, Korean version of Berg Balance Scale; K-MBI, Korean version of Modified Barthel Index.

${ }^{a}$ Mann-Whitney test, Student t-test.

\section{Length of hospital stays}

We analyzed hospital stays with respect as to whether the caregiver had attended the education program and while considering stroke severity (Fig. 1). In both groups, the length of stay tended to be longer in more severe patients, although this finding was not statistically significant.

\section{Functional status in the hospital}

We compared the score changes of the K-NIHSS, KMMSE, K-BBS, K-MBI at discharge between the control and experimental groups, but no significant differences were found (Fig. 2). Scrutinizing the improvement of neurologic impairment and functional gains from transfer to discharge for K-NIHSS, K-MMSE, K-BBS, and K-MBI scores, there were no differences between the mild and severe experimental subgroups and the patients did not vary with respect to whether their caregiver had attended the education program. On the other hand, in the moderate experimental subgroup significant improvements in

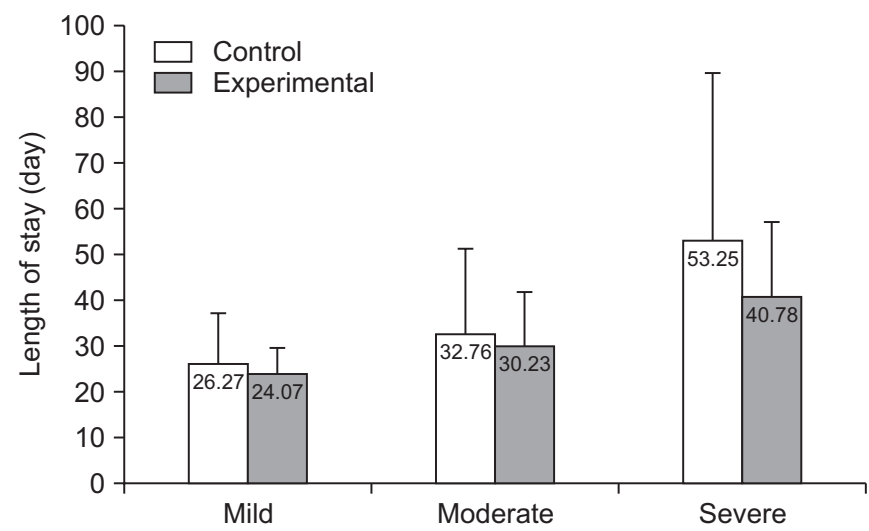

Fig. 1. Length of stay according to severity in two groups showed no significant difference $(\mathrm{p}>0.05)$.

K-NIHSS and K-BBS scores were observed in contrast to the control group; K-MMSE and K-MBI also tended to be higher (Table 4). 


\section{Satisfaction of caregivers}

In the experimental group, there were both family and formal caregiver subgroups. After the education program, the former showed an increase of 3.21 ( $\mathrm{SD}=2.71)$ in COPM scores (32.1\%) and formal caregivers displayed an elevation of 2.69 (SD=2.31, 26.9\%). No differences between family and formal caregivers were observed in the severe group, but the two subgroups showed significant increases in COPM scores for the moderate experimental subgroup. And also the formal caregivers of patients in the mild subgroup displayed a significant increase in satisfaction scores (Table 5).

\section{Caregiver burdens}

Both a tool for measuring burden for family caregivers

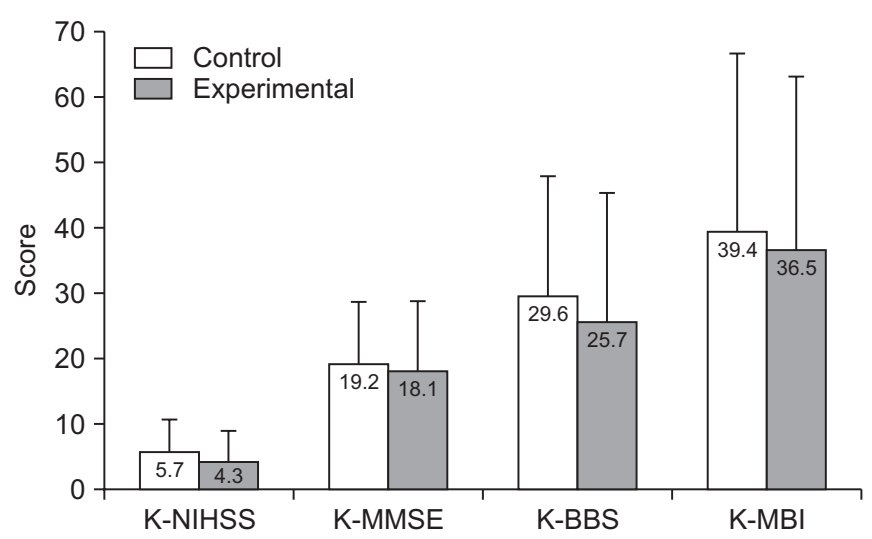

Fig. 2. Functional status in two groups after a caregiver's education program showed no significant difference ( $p>0.05$ ). K-NIHSS, Korean version of the National Institutes of Health Stroke Scale; K-MMSE, Korean version of Mini-Mental Status Examination; K-BBS, Korean version of Berg Balance Scale; K-MBI, Korean version of Modified Barthel Index. and an instrument to assess burnout for formal caregivers were used. The caregiver's education program caused the family caregivers burdens to decrease by $5.6 \%$ (mean $=0.25, \mathrm{SD}=0.5$ ) and those of formal caregivers to dropped by $5.0 \%$ (mean $=0.25, \mathrm{SD}=0.47$ ), although these differences were not statistically significant (Table 5).

\section{DISCUSSION}

In stroke patients, early recovery usually occurs within three months of onset. Subacute stroke recovery continues after three months and the treatment of chronic stroke aims to maintain functional status by use of compensatory techniques [12]. Furthermore, early intensive rehabilitation treatment is important in enabling patients to achieve maximum recovery [13]. A previous study reported that caregiver education about basic moving and handling skills, the facilitation of ADL as well as simple nursing tasks reduced caregiver burden, care costs, and helped patients to achieve independence at an early stage [14]. Another investigation found that family-mediated exercise intervention helped in the facilitation of patient recovery and that, importantly, additional exercise therapy contributed to functional recovery [15]. In yet another study, the stroke patients' caregiver burden was found to be greater than that of chronic disease patients' careers, such as dementia, hypertension or diabetes mellitus [16]. In particular, if stroke patients have low ADL abilities and are affected by paralysis, the heavily taxed caregivers and family members benefit from family education programs in terms of decreased physical, social, and emotional burdens [16]. However, in Korea, few studies have addressed the effect of caregiver education on the functional outcomes of stroke patients and caregiver burden [14-17].

Table 4. Functional changes after 4 weeks of caregiver's education according to severity

\begin{tabular}{|c|c|c|c|c|c|c|}
\hline & \multicolumn{2}{|c|}{ Mild } & \multicolumn{2}{|c|}{ Moderate } & \multicolumn{2}{|c|}{ Severe } \\
\hline & Control & Experimental & Control & Experimental & Control & Experimental \\
\hline K-NIHSS & $-1.18 \pm 1.14$ & $-1.33 \pm 1.60$ & $-3.30 \pm 3.61^{*}$ & $-5.21 \pm 4.03^{*}$ & $-6.62 \pm 6.50$ & $-7.55 \pm 3.04$ \\
\hline K-MMSE & $2.50 \pm 3.00$ & $4.50 \pm 4.45$ & $5.21 \pm 5.98$ & $5.11 \pm 5.57$ & $4.37 \pm 8.16$ & $2.92 \pm 4.23$ \\
\hline K-BBS & $17.20 \pm 15.06$ & $25.30 \pm 15.56$ & $13.83 \pm 14.26^{*}$ & $21.37 \pm 16.26^{*}$ & $9.37 \pm 18.90$ & $8.10 \pm 9.70$ \\
\hline K-MBI & $25.36 \pm 21.81$ & $33.41 \pm 25.80$ & $24.73 \pm 19.67$ & $31.29 \pm 22.19$ & $21.88 \pm 29.50$ & $18.50 \pm 26.00$ \\
\hline
\end{tabular}

Values are presented as mean \pm standard deviation.

K-NIHSS, Korean version of the National Institutes of Health Stroke Scale; K-MMSE, Korean version of Mini-Mental Status Examination; K-BBS, Korean version of Berg Balance Scale; K-MBI, Korean version of Modified Barthel Index. ${ }^{*} \mathrm{p}<0.05$, Student t-test. 


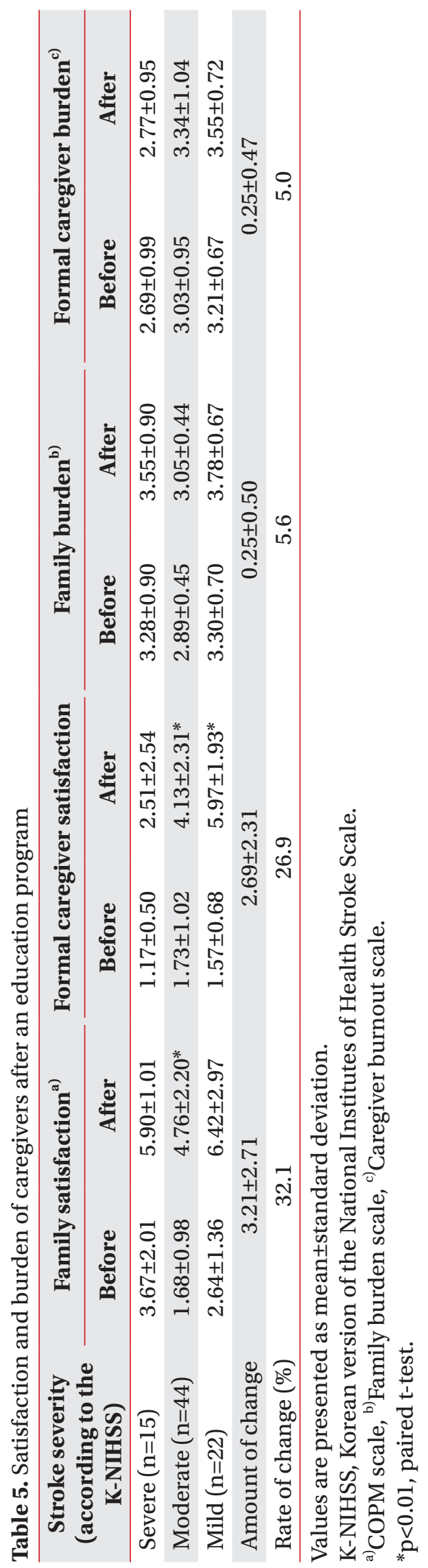

In this study, we investigated the effect of a caregiver educational program on rehabilitation therapy by examining length of hospital stay, impairment, and functional status in patients, as well as caregiver satisfaction and burden.

Caregivers of patients in the mild and moderate experimental subgroups showed a significant increase in satisfaction and a tendential decrease in burden. Similarly, it was reported that, after an education program, caregivers reported decreases in depression, strain, and an increase of satisfaction levels as compared to controls [15,18]. On the other hand, in severe stroke patients, goal-oriented, repetitive rehabilitation therapy cannot be performed; thus, sensory stimulation is the main approach of occupational and physical rehabilitation programs. Because rehabilitation programs performed by caregivers were restricted in this study, and since severe stroke patients showed less improvement, no increase in satisfaction could be observed in caregivers who provided care for this group as compared with that observed for the mild and moderately affected experimental subgroups.

We compared K-NIHSS, K-MMSE, K-MBI, K-BBS scores at transfer and discharge, but found no significant differences between the experimental and control groups. However, with respect to neurologic impairment, significant differences were observed in K-NIHSS and K-BBS scores between transfer and discharge for the moderate experimental subgroup. These improvements ascribed to the caregiver education program are consistent with findings that showed improvement of neurologic impairment after (physical and occupational) therapists provided an additional exercise program [19]. The merit of the present study is that it is the first one reporting improvements in non-healthcare workers.

The mild experimental subgroup revealed improvements in each of the above-mentioned variables at discharge. This finding is explained by a 'ceiling' effect, since patients with mild stroke acquire fewer overall benefits than more severely affected individuals. Furthermore, recovery in mild severity stroke patients often occurs spontaneously [15].

In the severe experimental subgroup, functional status did not change significantly after additional rehabilitation therapy by the caregiver's education program, maybe since severe stroke patients can tolerate additional treatment less and require more of the caregiver's time 
and effort than those who are mildly or moderately affected [20]. Furthermore, severe patients' brains are more damaged, their cognitive deficits are greater, they are less motivated; thus cannot readily profit from goal-oriented repetitive therapies.

Changes in K-MMSE and K-MBI scores between transfer and discharge did not differ between the control and experimental groups. In the present study, significant improvements in neurologic impairment were observed, but not in functional performance. It was previously reported that muscle strength gain did not directly lead to improvements in functional performance, and that functional independence could be achieved when a patient had a certain level of muscle strength [20].

Factors affecting functional outcomes have been identified, and depression and cognitive impairment after stroke were commonly observed to adversely affect functional recovery [21]. However, caregivers had a tendency to spend more time in physical exercise programs than cognitive enhancement ones and also caregiver education did not address depression; thus, it is possible that a lack of cognitive trainings and the presence of depression affected functional recoveries.

To achieve the greatest effects in the treatment of stroke patients, rehabilitation should start as soon as possible, being both intensive and task-specific [22]. Kim et al. [23] showed that intensive therapy promotes rapid recovery and reduced hospital stays. Usually, intensive rehabilitation therapy is applied for 45 minutes per session, 5 days a week, with realistic goals set [24].

In a Japanese study, the effects of rehabilitation treatment for 5 versus 7 days per week were compared using a Functional Independence Measure (FIM). The latter training group had a higher FIM level at discharge and a shorter mean duration of hospital stays [25]. The Japanese Ministry of Health, Labor, and Welfare acknowledged the importance of continuous intensive rehabilitation treatment for acute stroke patients and extended rehabilitation treatments to include weekends to the extent that $97.9 \%$ of institutions now undertake rehabilitation on Saturdays, $69.3 \%$ on Sundays, and $85.8 \%$ on official holidays [23]. However, in Korea, medical institutions cannot provide repetitive learning for stroke patients due to time, space, and human resource limitations [22]. Based on a previous study on intensive acute stroke treatment and our own findings, of the present study, we state that additional and more intensive treatments by caregivers that have undergone an education program could be instrumental in overcoming the lack of resources [23].

In today's society, the nuclear family unit is becoming more common; family organizations and values are changing. Due to changes in social structure, when a family member experiences stroke, other members find it difficult to offer care and to accept responsibility for the patient. Therefore, numbers of formal caregivers, who care for patients rather than family members, are gradually increasing [11]. In 2013, a survey of 1,584 Korean medical facilities revealed that the total number of formal caregivers was $17,821-14.7 \%$ in tertiary hospitals, $13.2 \%$ in general hospitals, and $18.0 \%$ in local hospitals [11].

There were 21 family caregivers and 60 formal caregivers, that is, there were three times as many of the latter. This suggests that education for formal caregivers is becoming an issue of growing importance.

Several limitations must be noted. First, patients were evaluated only at transfer and discharge and there were no long-term follow-ups. Therefore, research about management of longer duration with caregiver's education programs are needed, as well as studies on the maintenance of functioning. Second, we performed physical and occupational treatments, but not psychotherapy. In a review of various caregiver education programs, counseling was found to have momentous beneficial effects on quality of life, emotional status, and caregiver burden [20]. Hence, we believe that if counseling or other kinds of psychological support are included in education programs, their outcomes will be enhanced.

This study demonstrated that additional rehabilitation therapy as detailed in a caregiver's education program had a positive influence on patients' functional improvements and caregiver satisfaction. Furthermore, it showed that additional rehabilitation therapy promotes patient return to an optimized social life by enhancing functional improvements.

\section{CONFLICT OF INTEREST}

No potential conflict of interest relevant to this article was reported. 


\section{ACKNOWLEDGMENTS}

This work was supported by a research grant from Inha University.

\section{REFERENCES}

1. Roger VL, Go AS, Lloyd-Jones DM, Adams RJ, Berry JD, Brown TM, et al. Heart disease and stroke statistics. 2011 update: a report from the American Heart Association. Circulation 2011;123:e18-209.

2. Andersen HE, Eriksen K, Brown A, Schultz-Larsen K, Forchhammer BH. Follow-up services for stroke survivors after hospital discharge: a randomized control study. Clin Rehabil 2002;16:593-603.

3. Miller EL, Murray L, Richards L, Zorowitz RD, Bakas T, Clark $\mathrm{P}$, et al. Comprehensive overview of nursing and interdisciplinary rehabilitation care of the stroke patient: a scientific statement from the American Heart Association. Stroke 2010;41:2402-48.

4. Veerbeek JM, van Wegen E, van Peppen R, van der Wees PJ, Hendriks E, Rietberg M, et al. What is the evidence for physical therapy poststroke? A systematic review and meta-analysis. PLoS One 2014;9:e87987.

5. Van Peppen RP, Kwakkel G, Wood-Dauphinee S, Hendriks HJ, Van der Wees PJ, Dekker J. The impact of physical therapy on functional outcomes after stroke: what's the evidence? Clin Rehabil 2004;18:833-62.

6. Galvin R, Murphy B, Cusack T, Stokes E. The impact of increased duration of exercise therapy on functional recovery following stroke: what is the evidence? Top Stroke Rehabil 2008;15:365-77.

7. Kwakkel G, van Peppen R, Wagenaar RC, Wood Dauphinee S, Richards C, Ashburn A, et al. Effects of augmented exercise therapy time after stroke: a metaanalysis. Stroke 2004;35:2529-39.

8. Adams HP Jr, Davis PH, Leira EC, Chang KC, Bendixen $\mathrm{BH}$, Clarke WR, et al. Baseline NIH Stroke Scale score strongly predicts outcome after stroke: a report of the Trial of Org 10172 in Acute Stroke Treatment (TOAST). Neurology 1999;53:126-31.

9. Chenq YH, Rodger S, Polatjko H. Experiences with the COPM and client-centred practice in adult neurorehabilitation in Taiwan. Occup Ther Int 2002;9:167-84.

10. Suh MH, Oh KS. A study of well-being in caregivers caring for chronically ill family members. J Nurs Acad
Soc 1993;23:467-86.

11. Kim CS, Kim J. The impact of emotional labor on burnout for caregivers of stroke patients. Korean J Occup Health Nurs 2015;24:31-8.

12. Kwon SY, Hong SE, Kim EJ, Kim CH, Joa KL, Jung HY. Monitoring of functioning status in subjects with chronic stroke in South Korea using WHODAS II. Ann Rehabil Med 2016;40:111-9.

13. Wade DT, Wood VA, Hewer RL. Recovery after stroke: the first 3 months. J Neurol Neurosurg Psychiatr 1985; 48:7-13.

14. Kalra L, Evans A, Perez I, Melbourn A, Patel A, Knapp $\mathrm{M}$, et al. Training carers of stroke patients: randomised controlled trial. BMJ 2004;328:1099.

15. Galvin R, Cusack T, O'Grady E, Murphy TB, Stokes E. Family-mediated exercise intervention (FAME): evaluation of a novel form of exercise delivery after stroke. Stroke 2011;42:681-6.

16. Han KS, Kang ES, Kim HO, Yang MH, Kim SY. Effect of a family education program on the family burden of the stroke. J Korean Acad Psych Mental Health Nurs 2004;13:43-50.

17. Jung BC. The effects of rehabilitation education program for stroke patients and their family caregivers [master's thesis]. Chungju: Korea National University of Transportation; 2014.

18. Shyu YI, Chen MC, Chen ST, Wang HP, Shao JH. A family caregiver-oriented discharge planning program for older stroke patients and their family caregivers. J Clin Nurs 2008;17:2497-508.

19. Lincoln NB, Parry RH, Vass CD. Randomized, controlled trial to evaluate increased intensity of physiotherapy treatment of arm function after stroke. Stroke 1999;30:573-9.

20. Bohannon RW. Muscle strength and muscle training after stroke. J Rehabil Med 2007;39:14-20.

21. Saxena SK, Ng TP, Koh G, Yong D, Fong NP. Is improvement in impaired cognition and depressive symptoms in post-stroke patients associated with recovery in activities of daily living? Acta Neurol Scand 2007;115:339-46.

22. Sonoda S, Saitoh E, Nagai S, Kawakita M, Kanada Y. Full-time integrated treatment program, a new system for stroke rehabilitation in Japan: comparison with conventional rehabilitation. Am J Phys Med Rehabil 2004;83:88-93. 
23. Kim KH, Nam KW, Lee JS, Choi GY, Im HS, Lim JY, et al. Effects of full-time integrated self upper-extremity training program on functional recovery and length of stay in stroke patients. J Korean Acad Rehabil Med 2010;34:417-23.

24. Tokunaga M, Sannomiya K, Watanabe S, Nakanishi $\mathrm{R}$, Yamanaga H, Yonemitsu H, et al. Relationship between hospital ranking based on Functional Independence Measure (FIM) efficiency and factors related to rehabilitation system for stroke patients: a study of three hospitals participating in Kumamoto Stroke Liaison Critical Pathway. Jpn J Compr Rehabil Sci 2012;3:51-8.

25. Visser-Meily A, van Heugten C, Post M, Schepers V, Lindeman E. Intervention studies for caregivers of stroke survivors: a critical review. Patient Educ Couns 2005;56:257-67. 